\title{
The Mobile Proton Hypothesis in Fragmentation of Protonated Peptides: A Perspective
}

\author{
Robert Boyd ${ }^{a}$ and Árpád Somogyi ${ }^{b}$ \\ ${ }^{a}$ Institute for National Measurement Standards, National Research Council of Canada, Ottawa, Canada \\ ${ }^{\mathrm{b}}$ Department of Chemistry and Biochemistry, University of Arizona, Tucson, Arizona, USA
}

$\mathrm{T}$ he Distinguished Contribution Award of the American Society for Mass Spectrometry “-recognizes a focused, singular achievement in or contribution to fundamental or applied mass spectrometry, in contrast to awards that recognize lifetime achievement-a contribution that has had a significant impact on the fundamental understanding and/or practice of mass spectrometry." The hypothesis that has come to be known as the mobile proton model clearly satisfies both the fundamental and practical criteria. It is a pleasure to have been asked to contribute a brief introductory article to this special issue that honors Vicki Wysocki and Simon Gaskell, the principal originators and proponents of the model and the 2009 recipients of this prestigious award. Two excellent reviews cover the relevant literature up to about 2005 [1, 2]. The purpose of this short article is to attempt to view the mobile proton model relative to a wider perspective.

Application of mass spectrometry to determination of molecular structure relies on interpretation of fragment ion spectra, however obtained, using a set of rules that are the result of years of experience in extending concepts of classical physical-organic chemistry. Most of the fragmentation rules were derived from experience with positive ion mass spectra obtained using electron ionization. Probably the best-known guide to these interpretative rules is the book authored by McLafferty and Tureček [3]. The underlying theme of these "classical" rules is that the electron rearrangements involved in decomposition of an activated ion into two or more fragments are triggered by localization of charge (and/or unpaired electron spin in the case of radical ions) on specific sites within the molecular structure of the decomposing ion. It is true that these rules are almost entirely empirical, but their continuing practical success indicates that they must correspond to real phenomena in some sense. The introduction of chemical ionization, and later the powerful fast atom bombardment (FAB) [4], electrospray (ESI) [5], and MALDI [6] ionization techniques led to extension of the rules for fragmentations of molecular radical cations to even-electron molecular species formed by adduction of

Address reprint requests to Dr. R. K. Boyd, National Research Council, Bldg. M12, 1200 Montreal Road, Ottawa K1A0R6, Canada. E-mail: robert. boyd@nrc.ca simple ions, protons in the great majority of cases. Indeed, the mobile proton model can be regarded as an extension of these classical rules that permits their appropriate application to protonated peptides or other organic molecules. The main exceptions to interpretations based on triggering by localized charge sites are the charge-remote fragmentations [7] investigated by Gross and his colleagues starting in the late 1980s. These "pseudo-thermal" reactions are known $[8,9]$ to contribute to fragmentation of protonated peptides at high levels of internal activation, where they compete with the mechanisms subsumed by the mobile proton theory, particularly for singly-protonated peptides containing an Arg residue.

As emphasized previously [2], the mobile proton model is not a complete theory that can predict a fragment ion spectrum for any given protonated peptide, but rather a qualitative framework that permits appropriate application of interpretative rules based on charge-site localization. Essentially, the model assumes that for protonated peptides formed by soft ionization methods such as electrospray (ESI), the protons are initially localized on the most basic sites in the molecule. These sites are the $\mathrm{N}$-terminus and the side chains of basic amino acid residues, particularly Arg, Lys, and His. After ion activation the ionizing proton(s) can be transferred from the less-basic of these initially occupied sites to the various peptide linkages, thus triggering charge-site-initiated mechanisms of various kinds that provide the desired sequence ions. In other words, the mobile proton model also implies that heterogeneous populations of protonated forms can be generated upon ion activation and some of these forms are "fragmenting" structures, while others remain intact during the time frame of the mass spectrometer. This framework has now been extensively reviewed and its practical usefulness amply demonstrated [1,2].

Of course all useful new ideas appear to be simple and obvious once someone else has described them. To illustrate that the mobile proton model was not always regarded as "obvious" and was "linked" only later to the idea of ion populations generated by an "activated", i.e., "transferable" proton, one can cite some early work published in 1992 by one of the recipients of the Distinguished Contributions Award [10]. This paper was mainly concerned with demonstrating intraionic interactions in peptides containing cysteic acid plus 
either arginine or histidine residues, but also concluded that the findings were "consistent with the notion of the beneficial effect on low-energy decomposition spectra of protonated peptides of a population of precursor ions heterogeneous with respect to charge localization" [10]. Such hangovers from the concept of fragmentations triggered by charge sites due to "fixed" (i.e., not moveable) protons, so useful in rationalizing mass spectra of small molecules [3], were common at the time. As just one further example published in the same year, an investigation [11] of fragmentation of doublyprotonated tryptic peptides with an Arg or Lys residue at the C-terminus claimed that it was not possible to distinguish a mobile-proton model from a proposal that "the ion spray process may produce a population of $[\mathrm{M}+$ $2 \mathrm{H}]^{2+}$ ions with one of the protons localized on the N-terminus and the other distributed amongst the remaining nitrogen atoms including those in both the backbone and the side chains" [11]. This fence-sitting conclusion, demonstrating a reluctance to abandon the classical picture of initiation by localized charge sites formed in the ion source [3], was soon thereafter consigned to history by later work of Wysocki and Gaskell [12, 13]. Some of the most convincing experimental evidence for the validity of the mobile proton model is provided by statistical evaluations of large datasets of fragment ion spectra of a wide variety of protonated peptides [14, 15]. These statistical evaluations can help in further refining peptide sequencing programs that can result in more reliable identification of proteins on a large scale in proteomics applications.

The first hints of what was to become the mobile proton model can probably be traced to a very early study [16] (subsequently extended [17]) of d-labeled singly-protonated peptides formed by desorption chemical ionization or FAB. Although this work was concerned with the mechanism of the formation of $y$-series ions, it did raise the question of proton mobility in these reactions that intrinsically require proton (and $\mathrm{H}$-atom) transfer. The introduction of electrospray ionization [5] led in the early 1990s to extension of studies of fragmentation mechanisms to multiply-protonated peptides, and confirmed that sequestration of protons on highly basic sites prevented facile fragmentation at low collision energies to yield sequence information [18, 19]. Charge-remote mechanisms do provide such information at keV energies [8,9]. These early studies paved the way for the body of work described in the cited reviews [1, 2].

Besides experimental studies, theoretical (quantum chemical) calculations have also played a role in the development of the mobile proton model [12, 20, 21]. First, relatively simple bond order calculations clearly indicated that the amide bond order (or, somewhat imprecisely, the amide bond strength) was much lower (weaker) in amide-N-protonated forms than in amideO-protonated forms [12, 20]. These calculations also implied that even though the amide-O-protonated forms are more stable energetically, they do not neces- sarily (or exclusively) trigger amide bond fragmentation. These early "static" calculations, however, did not provide detailed information on the potential energy surfaces of protonated peptides, i.e., on transition states and reliable relative energetics of competitive (and consecutive) fragmentation processes. These important theoretical data are now available thanks to the development of the "pathways in competition" (PIC) model that has been described and reviewed eloquently in a review paper by Paizs and Suhai [21]. The "PIC" calculations reveal complex potential energy surfaces for protonated peptides with multiple possible fragmentation pathways. In spite of this complexity, the theoretical calculations based on the "PIC" model confirmed the experimental conclusions, and provided a link to several competing fragmentation mechanisms that follow the liberation of the mobile protons on to the peptide backbone. More recently, peptide fragment ion structures can be tested not only by theoretical calculations but also by newer experimental techniques, including variable wavelength infrared multiphoton dissociation (VW-IRMPD) spectroscopy and studies of ion mobility and gas-phase hydrogen/deuterium exchanges (HDX). These techniques have been used to study, for example, isomeric structures (oxazolone versus diketopiperazine) of $b_{n}$ ions [22-26].

Once the mobile proton model had become established, it led to more detailed studies of fragmentation mechanisms and ion structures. We believe that the main strength of the mobile proton model is a conceptual one: it triggered a large literature concerned with experimental and theoretical studies that led to a more comprehensive and consistent understanding of the fragmentation pathways of more complex singly and multiply charged peptide ions. Of course, despite the great progress that has been made in understanding peptide ion fragmentations within the conceptual framework of the mobile proton model, there is always much still to be learned.

Thus far in this perspective review we have tried to emphasize the importance of the mobile proton model within the context of our own discipline of organic and biological mass spectrometry. However, it seems appropriate to also briefly view the mobile proton concept in a wider scientific perspective. The generalized concept of mobile protons in chemistry has a long history, in that the Grotthuss mechanism [27] for the anomalously high conductivity of pure water was published in 1806 and is still the subject of active research [28, 29]. In enzyme catalysis, the importance of the intramolecular mobility of protons has earned a different name, "proton translocation" [30]. "Mobile protons" are now an essential feature in understanding the physico-chemical properties of certain organic crystals [31], and similarly in the development of $\mathrm{SiO}_{2}$ thin films as a potential rival for chips based on $\mathrm{Si}$ [32].

Application of the mobile proton concept to mass spectrometric analyses of peptides continues the tradition of elegant and useful conceptual frameworks that 
facilitate our understanding of physico-chemical phenomena and their applications. The mobile proton model is important not only for ion-chemistry but, in general, for biological mass spectrometry. This wider spectrum is well exemplified by the diversified original research contributions in this special issue of JASMS. Several of these papers revisit the question of structures and formation mechanisms of peptide b-ions. Thus, Molesworth and Van Stipdonk describe CID fragmentation patterns of protonated YARFLG and its permuted isomers to study the inhibition of formation of macrocyclic $b_{n}$ structures, and thus potential loss of sequence information resulting from cyclizationreopening by arginine residues regardless of position in the peptide. Paizs, Harrison et al. report a study of the effect of histidine residues on cyclization of $b_{5}$ and $b_{4}$ ions of HAAAAA and its permuted sequences, and demonstrate non-direct sequence ions via cyclization/ reopening chemistry in the CID product ion mass spectra of the $b$ ions when the His residue is near the C-terminus but no clear evidence for such ions when the His residue is near the $\mathrm{N}$-terminus. Polfer, Oomens et al. utilize a combination of VW-IRMPD spectroscopy and kinetic studies of H/D exchange to probe the competing formation of oxazolone versus macrocyclic $b_{2}-b_{4}$ ions of Leu-enkephalin, and confirm that the relative abundance of the macrocycle structure increases as a function of $b$ fragment size. The combination of VW-IRMPD spectroscopy and HDX techniques is exploited by Gucinski et al. to effectively separate and differentiate co-existing isomeric fragment ion structures (the $b_{5}$ ion and a water loss ion structure) derived from the related peptides YAGFL-OH, YAGFL- $\mathrm{NH}_{2}$, and $\mathrm{YAGFL}-\mathrm{OCH}_{3}$, and demonstrate that six sequence isomers of the free acid show a sequence dependence of relative isomer abundances. The paper by Chung and Tureček focuses on $z$-ions rather than b-ions, using a combination of electron-transfer dissociation, CID with $\mathrm{MS}^{3}$ and $\mathrm{MS}^{4}$ analysis, and electron structure theory calculations to demonstrate that backbone fragmentation of the $\mathrm{z}$-ions is not controlled by the radical site but proceeds as expected from the mobile proton model. The theme of radical peptide ions is also investigated by O'Hair et al. who formed radical cations of small peptides containing cysteine with the radical site centered on either the sulphur atom or on a backbone $\alpha$-carbon, and showed that transfer of hydrogen atoms (rather than protons) can occur between the $\alpha \mathrm{C}-\mathrm{H}$ of adjacent residues and the cysteinyl radical. Reid et al. describe a novel method of labeling surface-accessible lysine residues in proteins with a fixed-charge label that provides a unique neutral fragment (dimethyl sulphide) on CID of Glu-C peptides, thus solving the "needle in a haystack" problem of finding the surface peptides in the complex enzymatic digest.

Many other publications in the literature could be cited to exemplify the importance of the mobile proton model. However, the diversity of the scientific questions addressed in the papers in this special issue, and of the techniques used to explore them, is in itself an appropriate recognition of the advance in our understanding of gas-phase peptide ions that led to this Distinguished Contribution Award of the Society.

\section{References}

1. Wysocki, V. H.; Tsaprailis, G.; Smith, L. L.; Breci, L. A. Mobile and Localized Protons: A Framework for Understanding Peptide Dissociation. J. Mass Spectrom. 2000, 35, 1399-1406.

2. Wysocki, V. H.; Cheng, G.; Zhang, Q.; Hermann, K. A.; Beardsley, R. L.; Hilderbrand, A. E. Peptide Fragmentation Overview. In Principles of Mass Spectrometry Applied to Biomolecules, Laskin, J.; Lifshitz, C., Eds.; John Wiley and Sons: Hoboken, NJ, 2006; Chap VIII, p. 279-300.

3. McLafferty, F. W.; Tureček, F. Interpretation of Mass Spectra 4th ed.; University Science Books: Mill Valley, CA, 1993;

4. Barber, M.; Bordoli, R. S.; Sedgwick, R. D.; Tyler, A. N. Fast-Atom Bombardment of Solids (F AB): A New Ion Source for Mass Spectrometry. J. Chem. Soc. Chem. Commun. 1981, 335-326.

5. Fenn, J. B.; Mann, M.; Meng, C. K.; Wong, S. F.; Whitehouse, C. M. Electrospray Ionization-Principles and Practice. Mass Spectrom. Rev. 1990, 9, 37-70.

6. Hillenkamp, F.; Karas, J.; Beavis, R. C.; Chait, B. T. Matrix Assisted Laser Desorption/Ionization Mass Spectrometry of Biopolymers. Anal. Chem. 1991, 63, 1193A-1203A

7. Cheng, C.; Gross, M. L. Applications and Mechanisms of ChargeRemote Fragmentations. Mass Spectrom. Rev. 2000, 19, 398-420.

8. Johnson, R. S.; Martin S. A.; Biemann, K.; Stults J. T.; Throck Watson, J. Novel Fragmentation Process of Peptides by Collision-Induced Decomposition in a Tandem Mass Spectrometer: Differentiation of Leucine and Isoleucine. Anal. Chem. 1987, 59, 2621-2625.

9. Johnson, R. S.; Martin, S. A.; Biemann, K. Collision-Induced Fragmentation of $(\mathrm{M}+\mathrm{H})^{+}$Ions of Peptides. Side-Chain-Specific Sequence Ions. Int. J. Mass Spectrom. Ion Processes. 1988, 86, 137-154.

10. Burlet, O.; Yang, C.-Y.; Gaskell, S. J. Influence of Cysteine to Cysteic Acid Oxidation on the Collision-Activated Decomposition of Protonated Peptides: Evidence for Intraionic Interactions. J. Am. Soc. Mass Spectrom. 1992, 3, 337-344.

11. Tang, X.-J.; Boyd, R. K. An Investigation of Fragmentation Mechanisms of Doubly Protonated Tryptic Peptides. Rapid Commun. Mass Spectrom. 1992, 6, 651-657.

12. McCormack, A. L.; Somogyi, Á.; Dongré, A. R.; Wysocki, V. H. Fragmentation of Protonated Peptides: Surface-Induced Dissociation in Conjunction with a Quantum Mechanical Approach. Anal. Chem. 1993, 65, 2859-2872.

13. Tsaprailis, G.; Nair, H.; Somogyi, A.; Wysocki, V. H.; Zhong, W. Q.; Futrell, J. H.; Summerfield, S. G.; Gaskell, S. J. Influence of Secondary Structure on the Fragmentation of Protonated Peptides. J. Am. Soc. Mass Spectrom. 1999, 121, 5142-5154.

14. Kapp, E. A.; Schu1tz, F.; Reid, G. E.; Eddes, J. S.; Moritz, R. L.; O'Hair R. A. J.; Speed, T. P.; Simpson, R. J. Mining a Tandem Mass Spectrometry Database to Determine the Trends and Global Factors Influencing Peptide Fragmentation. Anal. Chem. 2003, 75, 6251-6254.

15. Huang, Y.; Triscari, J. M.; Tseng, G. C.; Pasa-Tolic, L.; Lipton, M. S.; Smith, R. D.; Wysocki, V. H. Statistical Characterization of the Charge State and Residue Dependence of Low-Energy CID Peptide Dissociation Patterns. Anal. Chem. 2005, 77, 5800-5813.

16. Mueller, D. R.; Eckersley, M.; Richter, W. R. Hydrogen Transfer Reactions in the Formation of "Y +2 " Sequence Ions from Protonated Peptides. Org. Mass Spectrom. 1988, 23, 217-222.

17. Kenny, P. T. M.; Nomoto, K.; Orlando, R. Fragmentation Studies of Peptides: The Formation of y Ions. Rapid Commun. Mass Spectrom. 1992, 6, 95-97.

18. Burlet, O.; Orkiszewski, R. S.; Ballard, K. D.; Gaskell, S. J. Charge Promotion of Low-Energy Fragmentations of Peptide Ions. Rapid Commun. Mass Spectrom. 1992, 6, 658-662.

19. Tang, X.-J.; Thibault, P.; Boyd, R. K. Fragmentation Reactions of Multiply-Protonated Peptides and Implications for Sequencing by Tandem Mass Spectrometry with Low-Energy Collision-Induced Dissociation. Anal. Chem. 1993, 65, 2824-2834.

20. Somogyi, Á.; Wysocki, V. H.; Mayer, I. The Effect of Protonation Site on Bond Strengths in Simple Protonated Peptides: Application of Ab Initio and MNDO Bond Orders and MNDO Energy Partitioning. J. Am. Soc. Mass Spectrom. 1994, 5, 704-717.

21. Paizs, B.; Suhai, S. Fragmentation Pathways of Protonated Peptides. Mass Spectrom. Rev. 2005, 24, 508-548.

22. Harrison, A. G.; Young, A. B.; Bleiholder, C.; Suhai, S.; Paizs, B. Scrambling of Sequence Information in Collision-Induced Dissociation of Peptides. J. Am. Chem. Soc. 2006, 128, 10364-10365.

23. Erlekam, U.; Bythell, B. J.; Scuderi, D.; Van Stipdonk, M.; Paizs, B. Maitre, P. Infrared Spectroscopy Fragments of Protonated Peptides. Direct Evidence for Macocyclic Structure of b5 Ions. J. Am. Chem. Soc. 2009, 131, 11503-11508.

24. Garcia, I.; Giles, K.; Bateman, R. H.; Gaskell, S. J. Evidence for Structural Variants of a- and b-Type Peptide Fragment Ions Using Combined Ion Mobility/Mass Spectrometry. J. Am. Soc. Mass Spectrom. 2008, 19, $609-613$. 
25. Garcia, I.; Giles, K.; Bateman, R. H.; Gaskell, S. J. Studies of Peptide aand b-Type Fragment Ions Using Stable Isotope Labeling and Integrated Ion Mobility/Tandem Mass Spectrometry. J. Am. Soc. Mass Spectrom. 2008, 19, 1781-1787.

26. Perkins, B. R.; Chamot-Rooke, J.; Yoon, S.-H.; Gucinski, A. C.; Somogyi, A.; Wysocki, V. H. Evidence of Diketopiperazine and Oxazolone Structures for HA b $\mathrm{b}_{2}$ - Ion. J. Am. Chem. Soc. 2009, 131, 17528-17529.

27. de Grotthuss, C. J. T. Sur la décomposition de l'eau et des corps qu'elle tient en dissolution à l'aide de l'électricité galvanique (On the decomposition of water and of solutes by electrical currents). Ann. Chim. 1806, 58, 54-73.

28. Agmon, N. The Grotthuss Mechanism. Chem. Phys. Lett. 1995, 244, 456-462.

29. Markovitch, O.; Chen, H.; Izvekov, S.; Paesani, F.; Voth, G. A.; Agmon, N. Special Pair Dance and Partner Selection: Elementary Steps in Proton Transport in Liquid Water. J. Phys. Chem. B 2008, 112, 9456-9466.
30. Blakely, M. P.; Ruiz, F.; Cachau, R.; Hazemann, I.; Meilleur, F.; Mitschler, A.; Ginell, S.; Afonine, P.; Ventura, O. N.; Cousido-Siah, A. Haertlein, M.; Joachimiak, A.; Myles, D.; Podjarny, A. Quantum Model of Catalysis Based on a Mobile Proton Revealed by Subatomic X-Ray and Neutron Diffraction Studies of h-Aldose Reductase. Proc. Nat. Acad. Sci. U.S.A. 2008, 105, 1844-1848.

31. Morrison, C. A.; Siddick, M. M.; Camp, P. J.; Wilson, C. C. Toward Understanding Mobile Proton Behavior from First Principles Calculation: The Short Hydrogen Bond in Crystalline Urea-Phosphoric Acid. J. Am. Chem. Soc. 2005, 127, 4042-4048.

32. Vanheusden, K.; Warren, W. L.; Devine, R. A. B.; Fleetwood, D. M. Schwank, J. R.; Shaneyfelt, M. R.; Winokur, P. S.; Lemnios, Z. J. Nonvolatile Memory Device Based on Mobile Protons in $\mathrm{SiO}_{2}$ Thin Films. Nature. 1997, 386, 587-589. 